This is an electronic reprint of the original article. This reprint may differ from the original in pagination and typographic detail.

Author(s): Antonello, S.; Dainese, T.; Pan, Fangfang; Rissanen, Kari; Maran, F.

Title: $\quad$ Electrocrystallization of Monolayer-Protected Gold Clusters : Opening the Door to Quality, Quantity, and New Structures

Year: $\quad 2017$

Version:

Please cite the original version:

Antonello, S., Dainese, T., Pan, F., Rissanen, K., \& Maran, F. (2017).

Electrocrystallization of Monolayer-Protected Gold Clusters : Opening the Door to Quality, Quantity, and New Structures. Journal of the American Chemical Society, 139(11), 4168-4174. https://doi.org/10.1021/jacs.7b00568

All material supplied via JYX is protected by copyright and other intellectual property rights, and duplication or sale of all or part of any of the repository collections is not permitted, except that material may be duplicated by you for your research use or educational purposes in electronic or print form. You must obtain permission for any other use. Electronic or print copies may not be offered, whether for sale or otherwise to anyone who is not an authorised user. 


\title{
Electrocrystallization of Monolayer-Protected Gold Clusters: Opening the Door to Quality, Quantity, and New Structures
}

\author{
Sabrina Antonello, ${ }^{\ddagger}$ Tiziano Dainese, ${ }^{\ddagger}$ Fangfang Pan, ${ }^{\dagger, \perp}$ Kari Rissanen, ${ }^{*}{ }^{\dagger}$ (1) and Flavio Maran ${ }^{*},+, \S_{(0)}$ \\ ${ }^{\ddagger}$ Department of Chemistry, University of Padova, via Marzolo 1, 35131 Padova, Italy \\ ${ }^{\dagger}$ Department of Chemistry, Nanoscience Center, University of Jyvaskyla, P.O. Box 35, 40014 Jyvaskyla, Finland \\ ${ }^{\S}$ Department of Chemistry, University of Connecticut, 55 North Eagleville Road, Storrs, Connecticut 06269, United States
}

\section{Supporting Information}

ABSTRACT: Thiolate-protected metal clusters are materials of ever-growing importance in fundamental and applied research. Knowledge of their single-crystal X-ray structures has been instrumental to enable advanced molecular understanding of their intriguing properties. So far, however, a general, reliable, chemically clean approach to prepare single crystals suitable for accurate crystallographic analysis was missing. Here we show that single crystals of thiolate-protected clusters can be grown in large quantity and very high quality by electrocrystallization. This method relies on the fact that charged clusters display a higher solubility in polar solvents than their neutral counterparts. Nucleation of the electrogenerated insoluble clusters directly
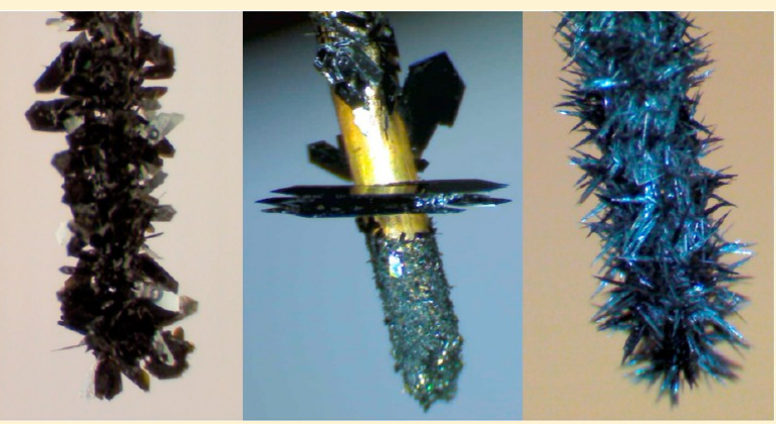
onto the electrode surface eventually leads to the formation of a dense forest of millimeter-long single crystals. Electrocrystallization of three known $\mathrm{Au}_{25}(\mathrm{SR})_{18}{ }^{0}$ clusters is described. A new cluster, $\mathrm{Au}_{25}\left(\mathrm{~S}-n \mathrm{C}_{5} \mathrm{H}_{11}\right)_{18}$, was also prepared and found to crystallize by forming bundles of millimeter-long $\mathrm{Au}_{25}$ polymers.

\section{INTRODUCTION}

Monolayer-protected metal clusters (MPCs) constitute a class of complex molecular systems of continuously growing fundamental $^{1-3}$ and applied interests, such as in sensing, ${ }^{4}$ nanomedicine, ${ }^{5,6}$ and catalysis. ${ }^{7,8}$ Since the ground-breaking discovery of a versatile methodology to make small MPCs, synthetic and purification procedures have been implemented to such a level that over the past few years several atomically precise clusters could be obtained. ${ }^{2,3,10,11}$ For some of these achievements it was instrumental to grow single crystals suitable for X-ray crystallographic analysis. ${ }^{2}$ These methods allowed reducing the size of the capping ligands down to a simple ethanethiolate ${ }^{12}$ or increasing the size of the Au core up to $\mathrm{Au}_{133} \cdot{ }^{13,14}$ Knowledge of the single-crystal crystallographic structures indeed provides an invaluable insight into understanding the fascinating properties of MPCs as well as a starting point to develop theories, predict possible structures, and devise experimental methodologies suitable to expand the scope of these molecular systems. Proper choice of the capping ligands, starting metal salts, and preparation conditions will conceivably expand further the number of stoichiometries achievable. For new clusters, determination of their structures and assessment of even minor structural features are essential for understanding structure-properties relationships and using them efficiently.

Despite important accomplishments in solving challenging structures, ${ }^{2,3}$ there are still cases that remain elusive or studies and applications that would require preparation of high-quality single crystals in larger quantities or size. This points to the urge of developing a versatile strategy to prepare single crystals suitable for X-ray crystallographic analysis and solid-state applications. Electrochemistry has the advantage of controlling the potential of a metal substrate where solid materials can be deposited. ${ }^{15-18}$ We thus envisaged that electrocrystallization could provide a reliable, chemically clean, and controlled way to prepare single crystals of MPCs. Here we describe an exceptionally efficient electrochemical method to prepare single crystals in large quantities. $\mathrm{Au}_{25}(\mathrm{SR})_{18}$, where $\mathrm{SR}$ indicates a thiolate, is a stable MPC whose study paved the way to developing synthetic strategies and catalytic applications, refining characterization techniques and computational parameters, understanding physicochemical properties of molecular MPCs, and developing specific investigation tools and methods. $712,19-24$ We thus focused on this "gold standard" and demonstrate here that electrocrystallization of known and still unknown $\mathrm{Au}_{25}(\mathrm{SR})_{18}{ }^{0}$ clusters is not only possible but also effectively yields, with a virtually $100 \%$ success rate, high-quality single crystals suitable to X-ray crystallographic analysis.

\section{RESULTS AND DISCUSSION}

Hypothesis. As a rule of thumb, uncharged metal clusters protected by low-polarity organic ligands are only soluble in apolar or low-polarity solvents. For this reason, the solvent of

Received: January 17, 2017

Published: March 10, 2017 
choice for electrochemistry has always been dichloromethane (DCM) ${ }^{25-28}$ On the other hand, charged $\mathrm{Au}_{25}$ clusters can be dissolved in both the same and other, more polar solvents. For example, the solubility of the iconic ${ }^{19} \mathrm{Au}_{25}\left(\mathrm{SC}_{2} \mathrm{H}_{4} \mathrm{Ph}\right)_{18}{ }^{-}$in acetonitrile $(\mathrm{MeCN})$ was originally employed to separate this cluster from its main byproduct, $\mathrm{Au}_{144}\left(\mathrm{SC}_{2} \mathrm{H}_{4} \mathrm{Ph}\right)_{60}$, and adventitious $\mathrm{Au}_{25}\left(\mathrm{SC}_{2} \mathrm{H}_{4} \mathrm{Ph}\right)_{18}{ }^{0.29}$ Our electrocrystallization strategy is based on the following salient aspects: (i) the initial and final oxidation states are chemically stable; (ii) the solvent/ electrolyte system must allow for dissolution of the initial charge state and grant insolubility of the electrochemically generated species; (iii) the current density has to be adjusted to sufficiently low values, thereby favoring crystallization on the electrode body as opposed to causing random precipitation of insoluble powder at the bottom of the electrochemical cell; (iv) crystallization should lead to a fairly conductive material suitable to make the electrode process occurring on the growing crystals. In the following, we first describe how to detect and characterize the formation of MPC deposits on the electrode surface. The macroscale electrocrystallization experiments are addressed next, focusing on the preparation and characterization of the crystals of three $\mathrm{Au}_{25}(\mathrm{SR})_{18}{ }^{0}$ clusters of already known structures. Finally, the electrochemical strategy is validated by growing and analyzing by X-ray crystallography the single crystals of a new cluster, which led to an important discovery.

Electrochemical Behavior. $\mathrm{Au}_{25}$ clusters are synthesized as diamagnetic anions, $\mathrm{Au}_{25}(\mathrm{SR})_{18}{ }^{-}$, that undergo oxidation when in solution under aerobic conditions. ${ }^{30}$ The resulting neutral, paramagnetic cluster $\mathrm{Au}_{25}(\mathrm{SR})_{18}{ }^{0}$ is indefinitely stable. Further oxidation to form the diamagnetic +1 charge state yields a species that is usually stable for several hours. ${ }^{20}$ In low-polarity media, the cyclic voltammetry $(\mathrm{CV})$ of $\mathrm{Au}_{25}$ clusters protected by alkyl or aromatic thiolates shows the same general features. $^{25-28}$ The two peaks corresponding to the $0 /-1$ and $+1 / 0$ redox couples are fully reversible. Further reduction (to form the dianion) or oxidation (to form, e.g., the di- and the trications) generate chemically labile species with lifetimes that depend on the charge state and may depend on the ligand, ${ }^{31-33}$ and this rules out the possibility of using such ions as starting materials. We thus used the anion as the initial charge state and focused on $\mathrm{Au}_{25}\left(\mathrm{SC}_{2} \mathrm{H}_{4} \mathrm{Ph}\right)_{18}{ }^{-}, \mathrm{Au}_{25}\left(\mathrm{~S}-n \mathrm{C}_{3} \mathrm{H}_{7}\right)_{18}{ }^{-}, \mathrm{Au}_{25}(\mathrm{~S}-$ $\left.n \mathrm{C}_{4} \mathrm{H}_{9}\right)_{18}{ }^{-}$, and $\mathrm{Au}_{25}\left(\mathrm{~S}-n \mathrm{C}_{5} \mathrm{H}_{11}\right)_{18}{ }^{-}$, which hereafter will be denoted as $\mathrm{C}_{2} \mathrm{Ph}^{-}, \mathrm{C}^{-}, \mathrm{C4}^{-}$, and $\mathrm{C5}^{-}$, respectively.

Figure $1 \mathrm{~A}$ shows the $\mathrm{CV}$ of $\mathrm{C4}^{-}$in DCM containing $0.1 \mathrm{M}$ tetrabutylammonium hexafluorophosphate (TBAH), a medium that has a dielectric constant $(\varepsilon)$ of $12.5 .^{28}$ At a low potential scan rate $(v)$, both peaks have a peak-to-peak separation of 59 $\mathrm{mV}$, which is typical of freely diffusing species undergoing a reversible electrode process. ${ }^{34}$ The same behavior is observed for the other clusters. In DCM, the separation between the two formal potential $\left(E^{\circ}\right)$ values (calculated as the half-sum of the anodic and cathodic peak potentials) is $0.303,0.316,0.327$, and $0.333 \mathrm{~V}$ for $\mathrm{C} 2 \mathrm{Ph},{ }^{31} \mathrm{C} 3, \mathrm{C} 4$, and $\mathrm{C} 5,{ }^{28}$ respectively. Figure $1 \mathrm{~B}$ (red trace) shows that the voltammetric oxidation of $\mathrm{C4}^{-}$ dramatically changes when studied in $\mathrm{MeCN}(\varepsilon=37.5)$. In this solvent, the second oxidation peak and the reduction peaks have the typical triangular shape associated with the release of a surface-confined species. ${ }^{35}$ Electrooxidation of the anion thus yields adsorbed $\mathrm{Au}_{25}(\mathrm{SR})_{18}{ }^{0}$ that is then desorbed at either the second oxidation peak (formation of the cation) or on the backward scan at potentials of the first peak (formation of the anion). Figure $1 \mathrm{~B}$ also shows the effect of progressively
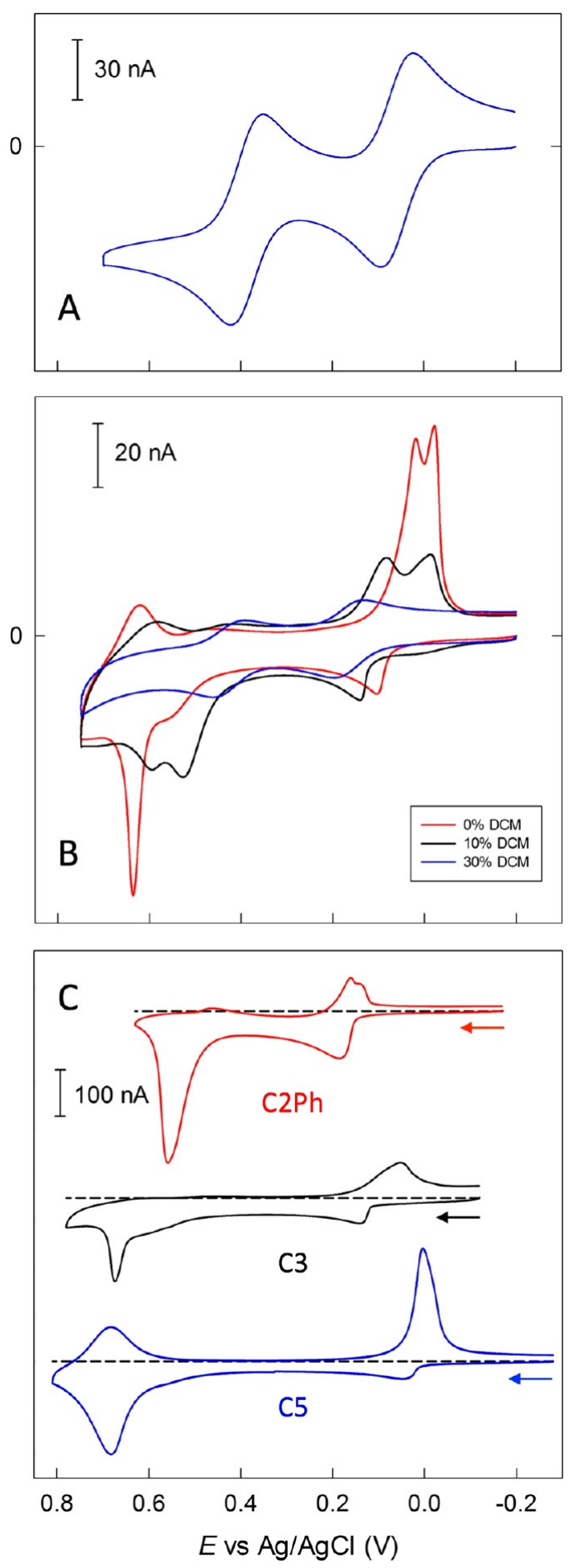

Figure 1. (A) CV curve of $3.5 \times 10^{-4} \mathrm{M} \mathrm{C}^{-}$in DCM. (B) CV curves of $6.8 \times 10^{-5} \mathrm{M} \mathrm{C4}^{-}$in $\mathrm{MeCN}$ (red) and after addition of 10 (black)

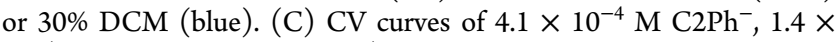
$10^{-4} \mathrm{M} \mathrm{C}^{-}$, and $1.7 \times 10^{-4} \mathrm{M} \mathrm{C5}^{-}$in $\mathrm{MeCN}$; the curves were arbitrarily displaced, and the dashed lines indicate the corresponding zero current levels. All CVs were obtained at $0.1 \mathrm{~V} \mathrm{~s}^{-1}$, in the presence of $0.1 \mathrm{M} \mathrm{TBAH}$, at $25{ }^{\circ} \mathrm{C}$. Arrows mark the initial potential-scan direction.

changing the composition of the solvent. The black trace refers to a $10 \%$ volume addition of DCM, whereas the blue trace shows that in the presence of $30 \%$ DCM, the peaks assume the typical diffusive shape observed in pure DCM (cf. Figure 1A). 
Figure 1C shows the electrochemical behavior of the other three clusters in MeCN. These observations do not depend on the electrode material, such as glassy carbon, $\mathrm{Au}$, and Pt.

For the sake of the present investigation, we will now focus on the first oxidation peak. Figure $2 \mathrm{~A}$ shows the increase in the
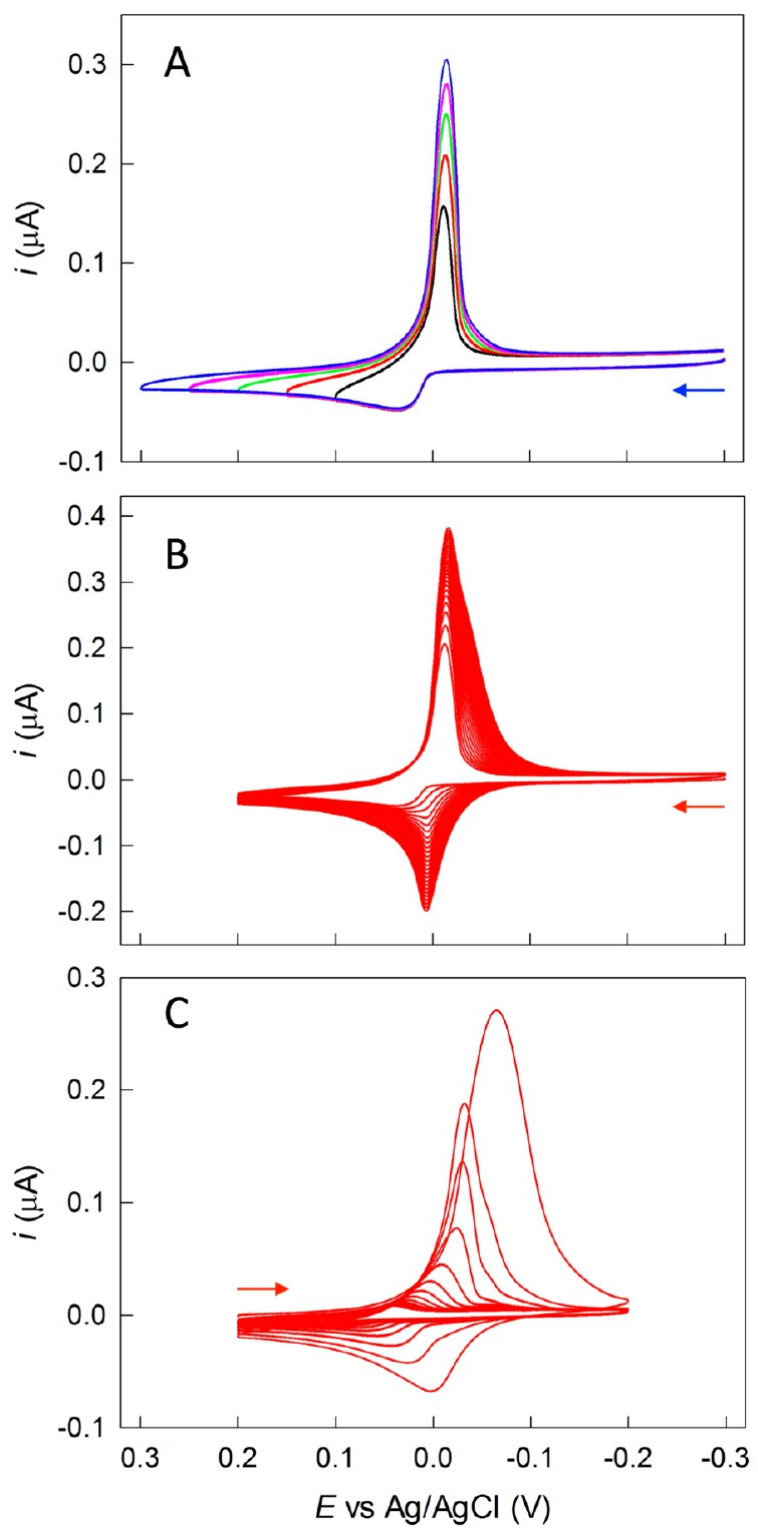

Figure 2. CVs of $1.4 \times 10^{-4} \mathrm{M} \mathrm{C5}^{-}$in $\mathrm{MeCN} / 0.1 \mathrm{M} \mathrm{TBAH}$ obtained at $0.1 \mathrm{~V} \mathrm{~s}^{-1}$ and $25^{\circ} \mathrm{C}$. (A) Effect of increasing the reversal potential on the $\mathrm{CV}$ of $\mathrm{C5}^{-}$. (B) Multicycle $\mathrm{CV}$ of $\mathrm{C5}^{-}$; the initial potential was set to $-0.3 \mathrm{~V}$. (C) Multicycle desorption of the $\mathrm{C} 5^{0}$ deposited in 50 cycles carried out as in plot B; here, the initial potential was set to 0.2 V.

reductive desorption peak upon increasing the reversal potential by $50 \mathrm{mV}$, which increases the electrolysis time by 1 s. Multiscan CV (Figure 2B) nicely illustrates that during a substantial part of the $\mathrm{CV}$ experiment, the oxidation product $\mathrm{Au}_{25}(\mathrm{SR})_{18}{ }^{0}$ does not leave the diffusion layer, while $\mathrm{Au}_{25}(\mathrm{SR})_{18}{ }^{-}$still diffuses toward the electrode, with the result of accumulating more cluster at the electrode surface. Upon continuous cycling between -0.3 and $0.2 \mathrm{~V}$ at $0.1 \mathrm{~V} \mathrm{~s}^{-1}$, both anodic and cathodic $i_{\mathrm{p}}$ values increase. Initially, the anodic peak potential $\left(E_{\mathrm{p}}\right)$ becomes progressively less positive, but then, after 5 cycles, $E_{\mathrm{p}}$ does not change anymore, and also this peak assumes the symmetric shape of an electrode-confined species, with a peak-to-peak separation of $22 \mathrm{mV}$. At the same time, the anodic peak broadens. Both peaks thus indicate formation of a continuously growing layer.

It is now interesting to evaluate how efficiently the cluster can be accumulated on the electrode surface after a given amount of $\mathrm{CV}$ cycles. We accumulated $\mathrm{C5}^{0}$ on the electrode during 50 cycles, as shown for 25 cycles in Figure 2B, and then extracted the electrode from the electrolytic solution at the end $(0.2 \mathrm{~V})$ of the final positive-going scan. The $\mathrm{Au}_{25}$-containing solution was removed from the cell, and fresh $\mathrm{MeCN} / 0.1 \mathrm{M}$ TBAH was added. The modified electrode was then immersed into the solution, while keeping its potential controlled at $0.2 \mathrm{~V}$. The potential was then scanned continuously between 0.2 and $-0.2 \mathrm{~V}$ (Figure 2C). Both peaks decrease with the number of cycles in keeping with the fact that diffusion of $\mathrm{C5}^{-}$toward the bulk, where no cluster is present, progressively depletes its concentration in the diffusion layer. Integration of the first reductive desorption peak yields the charge $Q$ associated with the quantity of cluster deposited and thus the surface coverage $\Gamma$. These quantities are related through equation $\Gamma=Q / A e$, where $A\left(\right.$ in $\left.\mathrm{cm}^{2}\right)$ is the electrochemical area (i.e., the true effective area) and $e$ is the charge of the electron (in $\mathrm{C}$ ); $\Gamma$ is thus expressed in clusters $\mathrm{cm}^{-2}$ and refers to the total amount of cluster deposited. Under the assumption that deposition occurs smoothly on the whole electrode surface, the number of layers can be calculated on the basis of simple considerations. $\mathrm{Au}_{25}$ clusters can be safely approximated to spheres. For an ideal hexagonal close-packed (hcp) lattice of equal spheres, one monolayer occupies $90.7 \%$ of the surface. For the nanoclusters' footprint, we use the Stokes radii. ${ }^{28}$ For C5, the footprint is thus $3.33 \mathrm{~nm}^{2}$, and the area effectively occupied by one single cluster is $3.67 \mathrm{~nm}^{2}$. Therefore, an ideal monolayer corresponds to a surface coverage $\left(\Gamma_{\text {mono }}\right)$ of $2.72 \times 10^{13}$ clusters $\mathrm{cm}^{-2}$ monolayer $^{-1}$. The ratio $\Gamma / \Gamma_{\text {mono }}$ thus shows that 56 ideal monolayers formed. Therefore, during the $50 \mathrm{CV}$ cycles used to form the deposit (at $0.1 \mathrm{~V} \mathrm{~s}^{-1}$ and within the above potential limits), an average of ca. $10 \%$ of the electrodeposited $\mathrm{C}^{\circ}$ is maintained after completion of one single CV cycle, and each cycle is responsible for the deposition of ca. one monolayer. The CV results thus point to a very efficient deposition of the electrogenerated neutral clusters on the electrode surface.

It is finally worth making some comments regarding similarities and differences in the $\mathrm{CV}$ behavior of the four clusters in $\mathrm{MeCN}$. Figure $1 \mathrm{~B}, \mathrm{C}$ and the aforementioned $\Delta E^{\circ}$ values show that the separation between the two oxidation peaks of C3, C4, and C5 is almost twice as large as in DCM, and this shows that, despite the more polar environment, which should decrease $\Delta E^{\circ},{ }^{25,31}$ oxidation of adsorbed $\mathrm{Au}_{25}(\mathrm{SR})_{18}{ }^{0}$ occurs at significantly more positive potentials than for soluble $\mathrm{Au}_{25}(\mathrm{SR})_{18}{ }_{18}$, whereas its reduction is more negative. This points to $\mathrm{Au}_{25}(\mathrm{SR})_{18}{ }^{0}$ electrodeposition as a favored process that creates a layer protecting the cluster from further oxidation to the corresponding cation. For $\mathrm{C} 2 \mathrm{Ph}$, the potential difference is smaller, but still larger ( 0.4 vs $0.3 \mathrm{~V}$ ) than in DCM. Figure 1B,C also shows that when the second peak is included, different patterns are observed for the clusters. For $\mathrm{C} 2 \mathrm{Ph}$ and $\mathrm{C} 3$, anodic desorption occurs, but then, on the backward scan, a rather featureless partial readsorption occurs in a wide potential range. The cases of C4 and C5 are different because the backward peak corresponding to the second anodic peak is clearly visible; for $\mathrm{C} 4$ and $\mathrm{C} 5$, the peak-to-peak separation is 10 and $0 \mathrm{mV}$, 


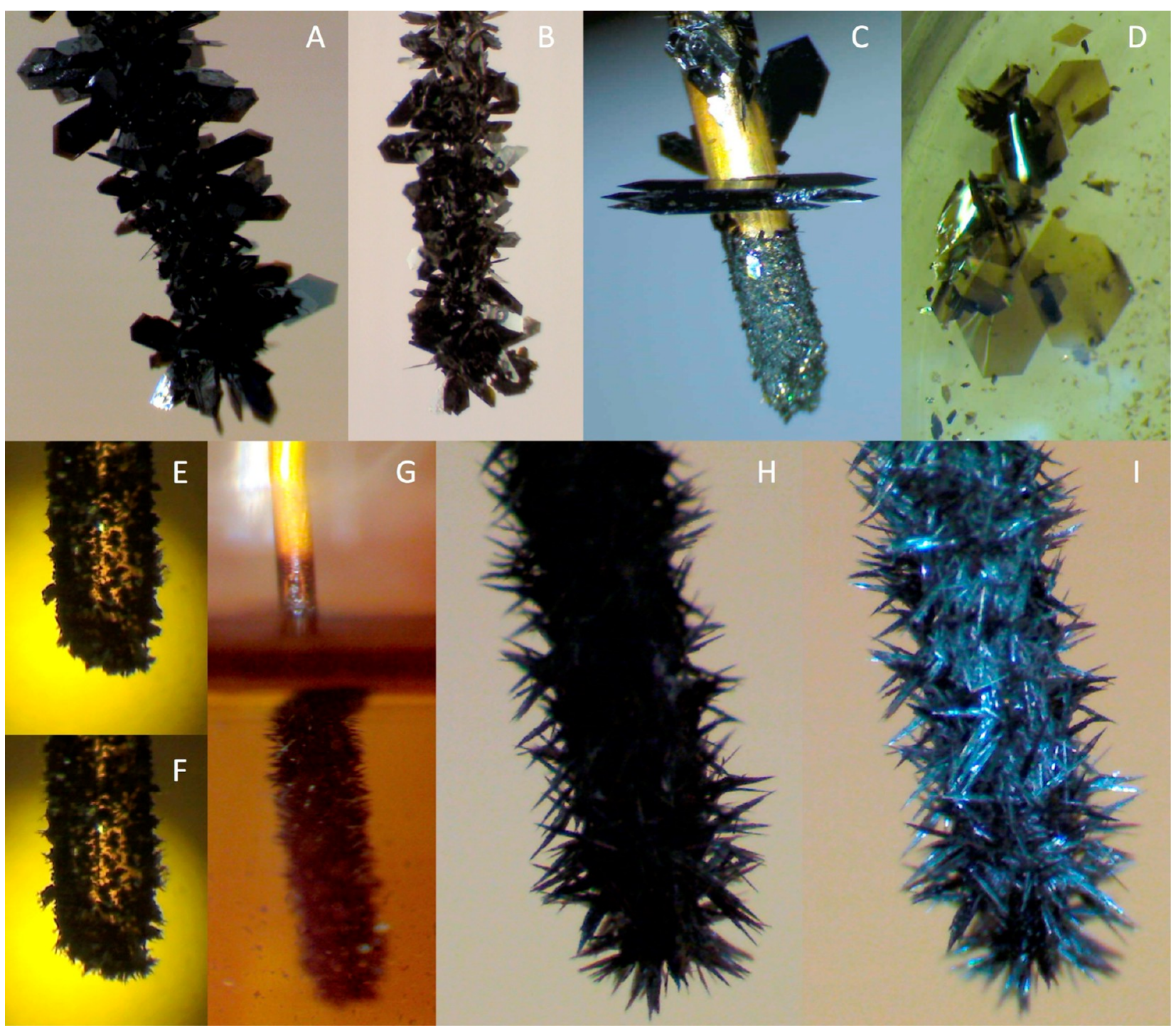

Figure 3. $(\mathrm{A}, \mathrm{B})$ Crystals of $\mathrm{C} 2 \mathrm{Ph}^{0}$ covering the gold wire at the end of electrolysis, after extraction of the electrode from the electrochemical cell. (C) Partially uncovered electrode that shows some large crystals of $\mathrm{C} 2 \mathrm{Ph}^{0}$. (D) Semitransparent crystals of $\mathrm{C}_{2} \mathrm{Ph}^{0}$ at the bottom of the electrochemical cell. (E,F) Electrode covered by crystals of $\mathrm{C}^{0}$, in the electrolytic solution, after 30 and $31 \mathrm{~h}$, respectively. (G) Electrode covered by crystals of $\mathrm{C}^{0}$ and still immersed in the electrolytic solution. (H,I) Different contrast images of the same electrode of $(\mathrm{G})$ after extraction from the cell.

respectively. Overall, desorption profiles suggest that the four clusters could be subdivided into two groups ( $\mathrm{C} 2 \mathrm{Ph}$ and $\mathrm{C} 3$, $\mathrm{C} 4$ and $\mathrm{C5}$ ) of somehow similarly behaving species.

Electrocrystallization of $\mathrm{C3}^{\circ}, \mathrm{C4}^{\circ}$, and $\mathrm{C} 2 \mathrm{Ph}^{0}$. These observations and conclusions were tested by carrying out macroelectrolyses. Because the structures of $\mathrm{C}^{0},{ }^{24} \mathrm{C}^{0}{ }^{36}$ and $\mathrm{C} 2 \mathrm{Ph}^{030}$ are known, we used these clusters to tests our electrocrystallization hypothesis. Electrolyses were conducted on deoxygenated quiescent solutions of $0.03-0.05 \mathrm{mM}$ $\mathrm{Au}_{25}(\mathrm{SR})_{18}{ }^{-}$in $\mathrm{MeCN} / 0.1 \mathrm{M} \mathrm{TBAH}$, at room temperature. We used a two-electrode configuration in which the working electrode was a $10-15 \mathrm{~mm}$ long, $0.75 \mathrm{~mm}$-thick gold wire. We applied very low currents, typically 50-200 nA. To avoid the risk of causing some oxidation of electrodeposited $\mathrm{Au}_{25}(\mathrm{SR})_{18}{ }^{0}$, which may occur because of the positive drift of the electrode potential toward the end of the controlled-current electrooxidation, we limited the extent of electrolysis to $80-95 \%$ of the $\mathrm{Au}_{25}(\mathrm{SR})_{18}{ }^{-}$present in solution. Due to the amount of cluster employed, 3-7 $\mathrm{mg}$, this implied electrolyzing the solutions for 6-11 days.
Formation of crystals may be already evident after a few hours, and the continuous growth of the deposit can be monitored with a camera. Figure $3 \mathrm{~A}, \mathrm{~B}$ shows that at the end of electrolysis, the density of crystals is very high (the specific case is $\left.\mathrm{C} 2 \mathrm{Ph}^{0}\right)$, and the whole electrode surface appears to be covered by identical, well-shaped crystals. It terms of size, we could grow crystals as long as $3 \mathrm{~mm}$, although longer crystals might be prepared by simply using a larger solution volume and longer electrolysis time. Figure $3 \mathrm{C}$ shows an electrode that was deliberately partially freed from the crystals after electrolysis. The image highlights the remarkable morphological quality of the crystals, as also evidenced by the reflection of the gold electrode on the surface of one of them. It also shows that the crystals may grow as closely spaced parallel sheets (three in Figure 3C). For this cluster, the crystals grow mainly in two directions, whereas the third dimension is maintained thin. For example, Figure 3D shows the semitransparent crystals that were shaken off the electrode of Figure $3 \mathrm{C}$ and fell to the bottom of the cell. These results suggest that electron hopping between the $\mathrm{C} 2 \mathrm{Ph}^{0}$ clusters immobilized in the crystal occurs 


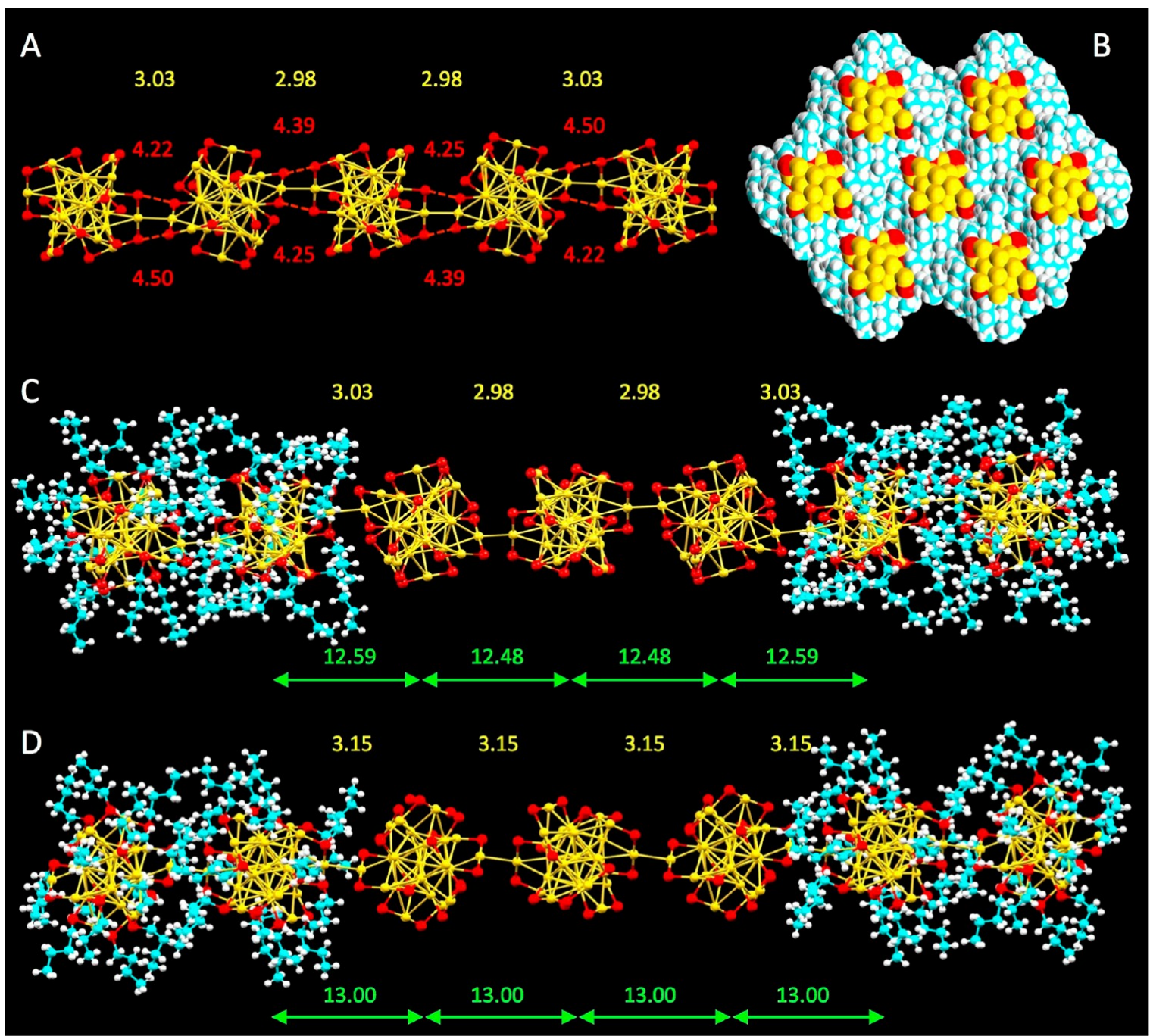

Figure 4. (A) Stick-and-ball view of the $\mathrm{Au}_{25} \mathrm{~S}_{18}$ skeletons of the MPCs found in the $\mathrm{Au}_{25}(\mathrm{SC} 5)_{18}{ }^{0}$ crystal, and relevant $\mathrm{S}-\mathrm{S}$ (red) and bonding $\mathrm{Au}-$ $\mathrm{Au}$ (yellow) distances. (B) View of the $1 \mathrm{D}$ chains along the polymer axis, in space-fill rendering. (C,D) Comparison between the $\mathrm{Au}_{25} \mathrm{~S}_{18} \mathrm{skeletons}$ of $\mathrm{Au}_{25}(\mathrm{SC5})_{18}{ }^{0}(\mathrm{C})$ and $\mathrm{Au}_{25}(\mathrm{SC} 4)_{18}{ }^{0}$ (D) with relevant distances ( $\mathrm{Au}-\mathrm{Au}$ bonds in yellow, $\mathrm{Au}_{\text {central }}-\mathrm{Au}_{\text {central }}$ in green) between the individual MPCs, where in both (C) and (D), the polymer wires have been partially peeled off ( $\mathrm{C}$ and $\mathrm{H}$ atoms). In all panels, the color codes are Au $=$ yellow, $\mathrm{S}=$ red, $\mathrm{C}=$ turquoise, and $\mathrm{H}=$ white.

preferentially in two directions and that the crystals act as an array of small electrodes.

The preparation of the $\mathrm{C} 3^{0}$ crystals shows the formation of more branched crystals. On the other hand, the electrosynthesis of the $\mathrm{C}^{0}{ }^{0}$ crystals leads to needle-like solids, which eventually grow to form triangular-shaped crystals. Figure 3E,F allows appreciating the progressive growth of needles in just $1 \mathrm{~h}$ electrolysis time. The observation of needle-like crystals is in keeping with our recent finding that $\mathrm{C} 4^{0}$ crystallizes by forming a linear polymer of $\mathrm{Au}_{25}$ clusters connected by $\mathrm{Au}-\mathrm{Au}$ bonds. ${ }^{36}$ For this cluster, the intercluster distance is much shorter along the axis of the polymer, which makes the crystal antiferromagnetic due to pairing of the spins of the otherwise paramagnetic individual clusters. This electronic coupling enhances electron conduction along the polymer axis and, therefore, the formation of needles.

Despite no specific attempt was made to optimize the experimental conditions, for all clusters, electrocrystallization was always successful. The X-ray crystallographic structures of the electrochemically prepared $\mathrm{C} 3^{\circ}, \mathrm{C} 4^{0}$, and $\mathrm{C} 2 \mathrm{Ph}^{0}$ crystals were compared with those already known. For $\mathrm{C} 3^{\circ}$ and $\mathrm{C} 4^{0}$, electrocrystallization gave the same structures previously described. ${ }^{24,36}$ The case of $\mathrm{C} 2 \mathrm{Ph}^{0}$ is particularly interesting. The first report was about a structure in orthorhombic space group Pccn with unit cell parameters $a=27.049, b=31.281, c=$ $18.593 \AA, \alpha=\beta=\gamma=90^{\circ},{ }^{30}$ whereas a very recent report described a structure in triclinic space group $P-1$ with unit cell parameters $a=16.174, b=17.746, c=17.830 \AA, \alpha=65, \beta=64$, and $\gamma=81^{\circ}$, but as a toluene solvate. ${ }^{37}$ Our electrocrystallized $\mathrm{C} 2 \mathrm{Ph}^{0}$ structure in orthorhombic space group Pnaa, with unit cell parameters $a=18.568, b=31.206, c=26.991 \AA, \alpha=\beta=\gamma$ $=90^{\circ}$, is markedly better (on thermal displacement parameters) than either of the previously reported structures (Figure S3).

Electrocrystallization of $\mathrm{C}^{\circ}$. The validated strategy was then applied to $\mathrm{C}^{-}$, whose single-crystal X-ray crystallographic structure has never been obtained previously. The electrolysis of $3.40 \times 10^{-5} \mathrm{M} \mathrm{C5}^{-}$was carried out at a constant current of $100 \mathrm{nA}$, which for the $\mathrm{Au}$ wire utilized corresponds to $0.30 \mu \mathrm{A}$ $\mathrm{cm}^{-2}$, for 7 days, which corresponds to $90 \%$ of the starting material $(4.6 \mathrm{mg})$. Figure $3 \mathrm{G}-\mathrm{I}$ shows the very nice forest of single crystals obtained at the end of electrolysis, whether still in solution or after extraction of the electrode. The formation of 
needle-like crystals and the fact that the electrode is fully covered by them indicates that crystallization occurs efficiently on the tip of the needle. This behavior is consistent with electron transfer occurring in an essentially monodirectional way, as already commented upon for $\mathrm{C} 4^{0}$. The quality and shape of the crystals, however, indicates that monodirectional formation of crystals is even more effective.

The crystals of $\mathrm{C}^{\circ}$ were studied by X-ray crystallography. One full and two halves of the $\mathrm{C}^{\circ}$ clusters connected via $\mathrm{Au}-$ $\mathrm{Au}$ intercluster bonds form the asymmetric unit of the unit cell. The general features of the $\mathrm{Au}_{25}$ structure are as observed in the other known thiolate-protected $\mathrm{Au}_{25}$ clusters. ${ }^{12,19,24,30,36}$ Regarding the spatial arrangement (Figure 4), on the other hand, we find the striking polymeric structure recently described for $\mathrm{C}^{0}{ }^{036}$ This prompts us to extract the common structural denominators of $\mathrm{C}^{0}$ and $\mathrm{C}^{\circ}$ and compare them with those of other $\mathrm{Au}_{25}$ MPCs to assess the possible reasons for the formation of intercluster $\mathrm{Au}-\mathrm{Au}$ bonds and the polymerization. The longer alkyl chains have more degrees of freedom, and thus, expectedly, disorder of the C5 chains is observed. However, the relative orientation of the alkyl chains is very similar to that noted in $\mathrm{C}^{0}$. The up-down-up or upup-down alkyl-chain conformations in $\mathrm{C}^{0}$ and $\mathrm{C5}^{0}$ with respect to the $S(R)-A u-S(R)-A u-S(R)$ plane are clearly different from those in $\mathrm{C} 2 \mathrm{Ph}^{0}$ and $\mathrm{C} 3^{0}$. This has a direct impact on the ligand orientation in the surface of the $\mathrm{C} 4^{0}$ and $\mathrm{C} 5^{\circ}$ clusters (Figure 4). This orientation of the alkyl chains opens up two opposite sides of the $\mathrm{Au}-\mathrm{S}-\mathrm{Au}$ staples to approach the adjacent MPC so close that formation of the intercluster $\mathrm{Au}-$ Au bond can take place and, therefore, leads to polymerization. The "twist-and-lock" mechanism ${ }^{36}$ that we previously proposed for $\mathrm{C}^{0}$ can still account for the situation observed for $\mathrm{C}^{0}$. Besides the many similarities, the difference between the two $\mathrm{Au}_{25}$ polymers is also noticeable. Whereas $\mathrm{C} 4^{0}$ shows a regular intercluster $\mathrm{Au}-\mathrm{Au}$ bond of $3.15 \AA$ (Figure 4D), $\mathrm{C}^{\circ}$ shows significantly shorter bonds of 2.98 and $3.03 \AA$ that alternate every two clusters in the polymeric sequence (Figure 4A,C). This results in a much shorter distance between the central $\mathrm{Au}$ atoms of neighboring $\mathrm{Au}_{25}$ clusters, 12.48 and $12.59 \AA$ in $\mathrm{C5}^{\circ}$ vs $13.00 \AA$ in $C 4^{0}$. These shorter distances point to better coupling between the orbitals of neighboring clusters and thus to an even more stable antiferromagnetic state for $\mathrm{C}^{\circ}$. As the minimum distance between gold atoms of clusters in neighboring rows is large $(8.3 \AA)$, the crystals of $\mathrm{C}^{0}$ can be seen as consisting of bundles of "insulated cables" formed of an organic layer surrounding a millimeter-long, $1 \mathrm{~nm}$-thick gold wire.

\section{CONCLUSIONS}

We have shown that by using a properly devised electrocrystallization approach, crystals of thiolate-protected clusters can be prepared in large amount, very high quality, and with a virtually $100 \%$ success rate. Galvanostatic electrooxidation generates insoluble $\mathrm{Au}_{25}(\mathrm{SR})_{18}{ }^{0}$ clusters that crystallize on the electrode surface and act as tiny electrodes to form a densely packed forest of crystals. X-ray crystallographic analysis showed that known structures are easily reproduced. The efficacy of the electrocrystallization approach is particularly evident in the improved structural features observed for the long-studied $\mathrm{Au}_{25}\left(\mathrm{SC}_{2} \mathrm{H}_{4} \mathrm{Ph}\right)_{18}{ }^{0}$. When this method was tested to prepare the crystals of a new $\mathrm{Au}_{25}$ clusters, we made the discovery that the $\mathrm{Au}_{25}$ polymerization phenomenon is more general than anticipated. We expect electrocrystallization to be successfully employed to solve the structure of new clusters, thereby enabling a molecular understanding of their fundamental properties, or prepare already known crystals in a larger amount and quality than accomplished by conventional methods. The ever-increasing information ${ }^{38}$ about the general electrochemical properties of a number of atomically precise MPCs, together with the support of accurate CV analysis of the lifetime of their charge states, will conceivably provide useful guidelines to develop specific electrocrystallization protocols.

\section{EXPERIMENTAL SECTION}

The $\mathrm{Au}_{25}(\mathrm{SR})_{18}{ }^{-}$clusters were prepared and purified as already described. ${ }^{20,24,36}$ Details are provided for C5 in the Supporting Information. The electrochemical experiments were carried out under an $\mathrm{Ar}$ atmosphere, in a glass cell at room temperature. For CV, the working electrode was a glassy carbon microdisk $\left(9.10 \times 10^{-4} \mathrm{~cm}^{2}\right)$, prepared and activated as already described. ${ }^{39}$ A very stable homemade $\mathrm{Ag} / \mathrm{AgCl}$ served as the reference electrode; ${ }^{40}$ in $\mathrm{MeCN}$, its potential was determined to be $0.201 \mathrm{~V}$ against the $\mathrm{KCl}$ saturated calomel electrode (SCE). For both electrolysis and CV experiments, the counter-electrode was a Pt plate inserted into a glass holder separated from the analyte solution with a G3 glass frit and a plug of electrolytesaturated methylcellulose gel. ${ }^{40}$ We used a CHI $660 \mathrm{c}$ electrochemical workstation. For CV experiments, the feedback correction was applied to minimize the ohmic drop between the working and the reference electrodes. Pictures of the electrodeposited crystals were taken with a Firefly GT800 high-precision video microscope. For this purpose, some experiments were conducted by using a quartz cuvette as the electrochemical cell. The Supporting Information provides detailed information about the $\mathrm{X}$-ray crystallographic analysis of the $\mathrm{Au}_{25}(\mathrm{~S}$ $\left.n \mathrm{C}_{5} \mathrm{H}_{11}\right)_{18}{ }^{0}$ and the $\mathrm{Au}_{25}\left(\mathrm{SC}_{2} \mathrm{H}_{4} \mathrm{Ph}\right)_{18}{ }^{0}$ single crystals. The crystal structures of $\mathrm{Au}_{25}\left(\mathrm{~S}-n \mathrm{C}_{5} \mathrm{H}_{11}\right)_{18}{ }^{0}$ and $\mathrm{Au}_{25}\left(\mathrm{SC}_{2} \mathrm{H}_{4} \mathrm{Ph}\right)_{18}{ }^{0}$ and their corresponding checkCIF files have been deposited to the Cambridge Crystallographic Data Centre with CCDC number of 1519225 and 1519226, respectively, and the data can be obtained free of charge via www.ccdc.cam.ac.uk/data_request/cif.

\section{ASSOCIATED CONTENT}

\section{Supporting Information}

The Supporting Information is available free of charge on the ACS Publications website at DOI: 10.1021 /jacs.7b00568.

Details on the synthesis and characterization of clusters, and X-ray crystallography information (PDF)

$\mathrm{X}$-ray crystallographic analysis of the $\mathrm{Au}_{25}\left(\mathrm{~S}-n \mathrm{C}_{5} \mathrm{H}_{11}\right)_{18}{ }^{0}$ single crystals (CIF)

X-ray crystallographic analysis of the $\mathrm{Au}_{25}\left(\mathrm{SC}_{2} \mathrm{H}_{4} \mathrm{Ph}\right)_{18}{ }^{0}$ single crystals (CIF)

\section{AUTHOR INFORMATION}

\section{Corresponding Authors}

*flavio.maran@unipd.it

*kari.t.rissanen@jyu.fi

ORCID $\odot$

Kari Rissanen: 0000-0002-7282-8419

Flavio Maran: 0000-0002-8627-6491

\section{Present Address}

${ }^{\perp}$ College of Chemistry, Central China Normal University, Wuhan, P. R. China, 430079.

\section{Notes}

The authors declare no competing financial interest.

\section{ACKNOWLEDGMENTS}

This work was financially supported by AIRC (FM, Project 12214: Innovative Tools for cancer risk assessment and early 
diagnosis - 5 per mille) and the Academy of Finland (KR, grant nos. 263256 and 292746). We thank Alfonso Venzo for insights into the NMR analysis.

\section{REFERENCES}

(1) Murray, R. W. Chem. Rev. 2008, 108, 2688-2720.

(2) Protected Metal Clusters: From Fundamentals to Applications. In Frontiers of Nanoscience; Tsukuda, T., Häkkinen, H., Eds.; Elsevier: Amsterdam, 2015; Vol. 9.

(3) Jin, R.; Zeng, C.; Zhou, M.; Chen, Y. Chem. Rev. 2016, 116, 10346-10413.

(4) Howes, P. D.; Chandrawati, R.; Stevens, M. M. Science 2014, 346, 1247390.

(5) Saha, K.; Agasti, S. S.; Kim, C.; Li, X.; Rotello, V. M. Chem. Rev. 2012, 112, 2739-2779.

(6) Tao, Y.; Li, M.; Ren, J.; Qu, X. Chem. Soc. Rev. 2015, 44, 86368663.

(7) Li, G.; Jin, R. Acc. Chem. Res. 2013, 46, 1749-1758.

(8) Yamazoe, S.; Koyasu, K.; Tsukuda, T. Acc. Chem. Res. 2014, 47, 816-824.

(9) Brust, M.; Walker, M.; Bethell, D.; Schiffrin, D. J.; Whyman, R. J. Chem. Soc., Chem. Commun. 1994, 801-802.

(10) Qian, H.; Zhu, M.; Wu, Z.; Jin, R. Acc. Chem. Res. 2012, 45, $1470-1479$.

(11) Negishi, Y.; Kurashige, W.; Niihori, Y.; Nobusada, K. Phys. Chem. Chem. Phys. 2013, 15, 18736-18751.

(12) Dainese, T.; Antonello, S.; Gascón, J. A.; Pan, F.; Perera, N. V.; Ruzzi, M.; Venzo, A.; Zoleo, A.; Rissanen, K.; Maran, F. ACS Nano 2014, 8, 3904-3912.

(13) Dass, A.; Theivendran, S.; Nimmala, P. R.; Kumara, C.; Jupally, V. R.; Fortunelli, A.; Sementa, L.; Barcaro, G.; Zuo, X.; Noll, B. C. J. Am. Chem. Soc. 2015, 137, 4610-4613.

(14) Zeng, C.; Chen, Y.; Kirschbaum, K.; Appavoo, K.; Sfeir, M. Y.; Jin, R. Science Adv. 2015, 1, e1500045.

(15) Batail, P.; Boubekeur, K.; Fourmigué, M.; Gabriel, J.-C. P. Chem. Mater. 1998, 10, 3005-3015.

(16) Gurrappa, I.; Binder, L. Sci. Technol. Adv. Mater. 2008, 9, 043001.

(17) Campagnol, N.; Van Assche, T. R. C.; Li, M.; Stappers, L.; Dinca, M.; Denayer, J. F. M.; Binnemans, K.; De Vose, D. E.; Fransaer, J. J. Mater. Chem. A 2016, 4, 3914-3925.

(18) Osaka, T.; Komaba, S.; Momma, T. Conductive Polymers: Electroplating of Organic Films. In Modern Electroplating, 5th ed.; Schlesinger, M., Paunovic, M., Eds.; Wiley: New York, 2010; pp 421432.

(19) Parker, J. F.; Fields-Zinna, C. A.; Murray, R. W. Acc. Chem. Res. 2010, 43, 1289-1296.

(20) Venzo, A.; Antonello, S.; Gascón, J. A.; Guryanov, I.; Leapman, R. D.; Perera, N. V.; Sousa, A.; Zamuner, M.; Zanella, A.; Maran, F. Anal. Chem. 2011, 83, 6355-6362.

(21) Yau, S. H.; Varnavski, O.; Goodson, T., III Acc. Chem. Res. 2013, $46,1506-1516$.

(22) Knoppe, S.; Bürgi, T. Acc. Chem. Res. 2014, 47, 1318-1326.

(23) Fernando, A.; Weerawardene, K. L. D. M.; Karimova, N. V.; Aikens, C. M. Chem. Rev. 2015, 115, 6112-6216.

(24) Agrachev, M.; Antonello, S.; Dainese, T.; Gascón, J. A.; Pan, F.; Rissanen, K.; Ruzzi, M.; Venzo, A.; Zoleo, A.; Maran, F. Chem. Sci. 2016, 7, 6910-6918.

(25) Lee, D.; Donkers, R. L.; Wang, G.; Harper, A. S.; Murray, R. W. J. Am. Chem. Soc. 2004, 126, 6193-6199.

(26) Guo, R.; Murray, R. W. J. Am. Chem. Soc. 2005, 127, 1214012143.

(27) Antonello, S.; Arrigoni, G.; Dainese, T.; De Nardi, M.; Parisio, G.; Perotti, L.; René, A.; Venzo, A.; Maran, F. ACS Nano 2014, 8, $2788-2795$.

(28) Antonello, S.; Dainese, T.; De Nardi, M.; Perotti, L.; Maran, F. ChemElectroChem 2016, 3, 1237-1244.
(29) Donkers, R. L.; Lee, D.; Murray, R. W. Langmuir 2004, 20, 1945-1952.

(30) Zhu, M.; Eckenhoff, W. T.; Pintauer, T.; Jin, R. J. Phys. Chem. C 2008, 112, 14221-14224.

(31) Antonello, S.; Holm, A. H.; Instuli, E.; Maran, F. J. Am. Chem. Soc. 2007, 129, 9836-9837.

(32) Antonello, S.; Perera, N. V.; Ruzzi, M.; Gascón, J. A.; Maran, F. J. Am. Chem. Soc. 2013, 135, 15585-15594.

(33) Antonello, S.; Dainese, T.; Maran, F. Electroanalysis 2016, 28, 2771-2776.

(34) Nicholson, R. S.; Shain, I. Anal. Chem. 1964, 36, 706-723.

(35) Bard, A. J.; Faulkner, L. R. Electrochemical Methods, Fundamentals and Applications, 2nd ed.; John Wiley \& Sons: New York, 2001; Chapter 14, pp 580-631.

(36) De Nardi, M.; Antonello, S.; Jiang, D.; Pan, F.; Rissanen, K.; Ruzzi, M.; Venzo, A.; Zoleo, A.; Maran, F. ACS Nano 2014, 8, 85058512.

(37) Tofanelli, M. A.; Salorinne, K.; Ni, T. W.; Malola, S.; Newell, B.; Phillips, B.; Häkkinen, H.; Ackerson, C. J. Chem. Sci. 2016, 7, 18821890.

(38) Antonello, S.; Maran, F. Curr. Opin. Electrochem. 2017, 2, 1825 .

(39) Meneses, A. B.; Antonello, S.; Arévalo, M.-C; Maran, F. Electroanalysis 2006, 18, 363-370.

(40) Farnia, G.; Maran, F.; Sandonà, G.; Severin, M. G. J. Chem. Soc., Perkin Trans. 2 1982, 1153-1158. 